This item was submitted to Loughborough's Research Repository by the author.

Items in Figshare are protected by copyright, with all rights reserved, unless otherwise indicated.

\title{
The measurement of transient aerodynamics using an oscillating model
}

\section{facility}

PLEASE CITE THE PUBLISHED VERSION

http://dx.doi.org/10.4271/2006-01-0338

PUBLISHER

(C) SAE International

VERSION

VoR (Version of Record)

LICENCE

CC BY-NC-ND 4.0

\section{REPOSITORY RECORD}

Passmore, Martin A., and Shuhaimi Mansor. 2010. "The Measurement of Transient Aerodynamics Using an Oscillating Model Facility”. figshare. https://hdl.handle.net/2134/6710. 


\title{
The Measurement of Transient Aerodynamics Using an Oscillating Model Facility
}

\author{
M. A. Passmore and S. Mansor \\ Loughborough University
}

Reprinted From: Vehicle Aerodynamics 2006

(SP-1991)

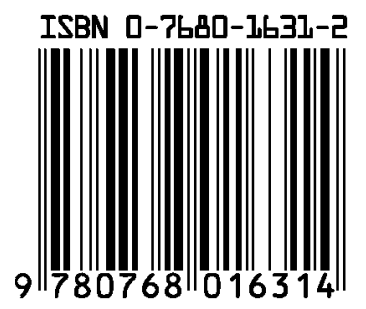


The Engineering Meetings Board has approved this paper for publication. It has successfully completed SAE's peer review process under the supervision of the session organizer. This process requires a minimum of three (3) reviews by industry experts.

All rights reserved. No part of this publication may be reproduced, stored in a retrieval system, or transmitted, in any form or by any means, electronic, mechanical, photocopying, recording, or otherwise, without the prior written permission of SAE.

For permission and licensing requests contact:

SAE Permissions
400 Commonwealth Drive
Warrendale, PA 15096-0001-USA
Email: permissions@ @ sae.org
Tel: $\quad 724-772-4028$
Fax: $\quad 724-776-3036$

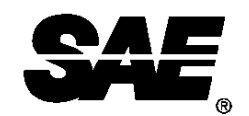

Global Mobility Database ${ }^{\circledast}$

All SAE papers, standards, and selected books are abstracted and indexed in the Global Mobility Database.

For multiple print copies contact:

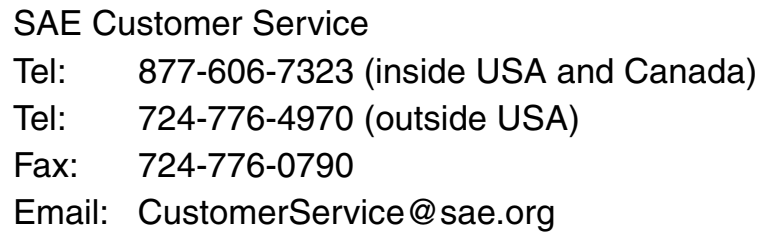

\section{ISSN 0148-7191}

\section{Copyright $\subset 2006$ SAE International}

Positions and opinions advanced in this paper are those of the author(s) and not necessarily those of SAE. The author is solely responsible for the content of the paper. A process is available by which discussions will be printed with the paper if it is published in SAE Transactions.

Persons wishing to submit papers to be considered for presentation or publication by SAE should send the manuscript or a 300 word abstract to Secretary, Engineering Meetings Board, SAE.

\section{Printed in USA}




\title{
The Measurement of Transient Aerodynamics Using an Oscillating Model Facility
}

\author{
M. A. Passmore and S. Mansor \\ Loughborough University
}

Copyright $\odot 2006$ SAE International

\begin{abstract}
A method for the estimation of transient aerodynamic data from dynamic wind tunnel tests has been developed and employed in the study of the unsteady response of simple automotive type bodies. The paper describes the facility and analysis techniques employed and reports the results of a parametric study of model rear slant angle and of the influence of C-pillar strakes. The model is shown to exhibit damped, self-sustained and self-excited behaviour. The transient results are compared with quasi-steady predictions based on conventional tunnel balance data through the calculation of derivative magnification factors . For all slant angles tested the results show that the quasi-steady prediction is a poor estimate of the real transient behaviour. In addition the slant angle is shown to have significant effect on the level of unsteadiness. The addition of Cpillar strakes is shown to stabilise the flow with even small height strakes yielding responses well below that of steady-state.
\end{abstract}

\section{INTRODUCTION}

The development of streamlined or low drag car bodies to satisfy the demand for better fuel economy, has tended to increase the sensitivity of vehicles to crosswind disturbances. This additional sensitivity arises because the drag reduction techniques have generally involved rounding of the front end profiles and the region around the rear pillar. In the presence of crosswinds this can give rise to differences between front and rear sideforce and hence generate significant yaw moments that tend to destabilize the vehicle. Under unsteady conditions the added body curvature can also lead to uncertain and variable separation resulting in unsteady aerodynamic loads. Though these loads may not destabilize the vehicle they can lead to a feeling of poor refinement and so are of concern to the vehicle manufacturers. There is clearly a need to improve our understanding of the unsteady case and for the development of techniques to measure and quantify a vehicle's susceptibility to crosswind inputs at an early stage in the vehicle development process.
A number of authors have reported work that attempts to simulate transient conditions. These include techniques that oscillate the flow over a stationary model [1], [10] move the model in steady flow [2], [4], [8] or alternatively create a crosswind gust in the main flow over a stationary model [12]. However, the results are not consistent, with some reporting that the steady state loads are a conservative estimate of the dynamic case [1], [4], while others indicate overshoot under transient conditions [2], [10], [12].

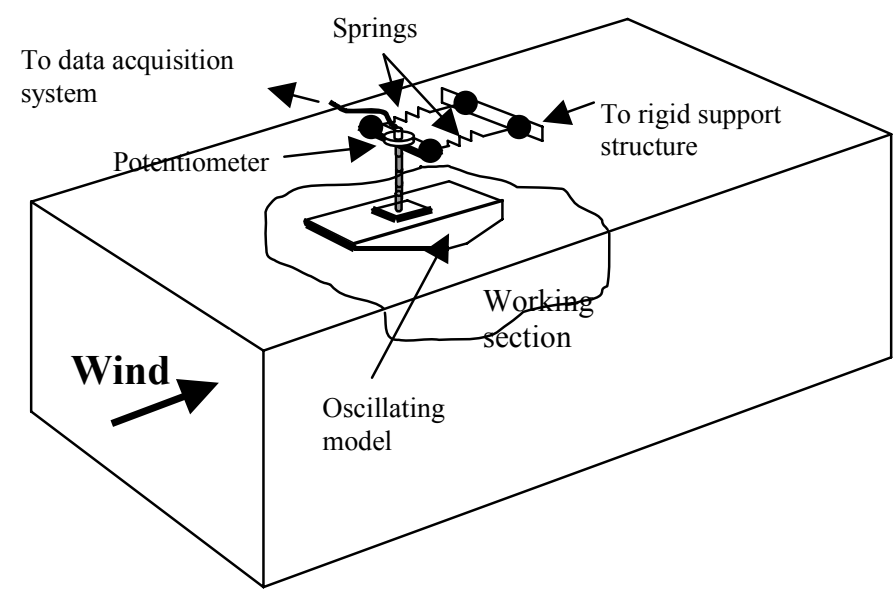

Figure 1 Schematic of experimental setup.

Previous work by the authors [11] has described the development of an oscillating model facility such as that illustrated in Figure 1. The rig consists of a simple bluff body (Davis model) constrained to oscillate with a single degree of freedom of pure yawing motion. The oscillatory mechanism is mounted to a rigid support structure outside the working section and a circular section steel rod, of $20 \mathrm{~mm}$ diameter, passes through a clearance hole in the roof. The model is mounted to the end of the support rod and is free to rotate in yaw. The combination of the flow and the model oscillation then represents an unsteady condition. The externally mounted pair of springs can be changed to control the oscillation frequency and hence reduced frequency. The frequency range of importance in crosswind studies has been identified as approximately 0.2 to $2.0 \mathrm{~Hz}$, [5], [13]. 
At motorway speeds this corresponds to reduced frequencies between approximately 0.09 and 0.9 where reduced frequency is defined as, $K m=\frac{\pi f L}{U}$.

The model time response is recorded in wind-on and wind-off conditions from the precision potentiometer mounted on the top of the shaft, and analyzed to extract the aerodynamic data. The results presented by the authors showed good agreement between this facility and an alternative approach using flapping aero-foils to generate a sinusoidal wind input to a static model [10].

In the paper presented here the oscillating model method is used in a parametric study of the effect of rear slant angle and C-pillar strake on the transient aerodynamics of a simple automotive body.

\section{EXPERIMENTAL SETUP}

The oscillating rig is mounted on the roof of the $1.9 \mathrm{~m} \mathrm{x}$ $1.3 \mathrm{~m}$ low speed wind tunnel in the department of Aeronautical and Automotive Engineering at Loughborough University. At the centre of the empty working section the turbulence intensity is approximately $0.15 \%$ measured at $40 \mathrm{~m} / \mathrm{s}$. The boundary layer thickness at the centre of the working section, on the floor, is $60 \mathrm{~mm}$ and is assumed to be the same at the centre of the working section roof. The wind tunnel has a working range of 0 to $45 \mathrm{~m} / \mathrm{s}$.

The tunnel is equipped with a precision 6 component external balance located under the working section. In the work reported here this is used to measure the static yaw moment and side-force response (as a function of yaw) of each model case.

The model employed in the study is a simplified bluff body that represents a road vehicle shape (Davis model). A schematic of the model equipped with the $20^{\circ}$ rear slant angle is shown in Figure 2. The main model is constructed from fiber-glass and the alternative slant angles added using a lightweight foam. This minimizes any changes in model inertia. In addition to the $20^{\circ}$ slant the parametric study considers rear slants of $0,10,30$ and 40 degrees. The model represents a tunnel blockage of $1.4 \%$ thus having a very small blockage effect [3].

Prior to running each experiment the model is aligned with the tunnel using adjustors mounted at the end of each of the springs. The cross-arm is then deflected and released so that the model is free to oscillate. The response from the potentiometer is recorded via a 12 bit $\mathrm{ADC}$, at a rate of $1 \mathrm{kHz}$. The resolution of measurement is $2.442 \mathrm{mV}(0.02442 \%$ of full scale $)$. The experiment is then repeated for a range of tunnel speeds.

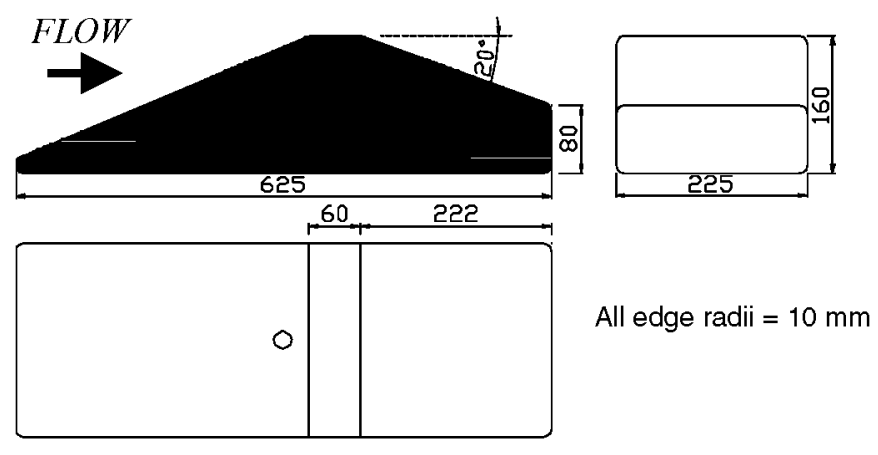

Figure 2 Davis model dimensions.

\section{BACKGROUND TO THE ANALYSIS}

The method of analysis is described in some detail elsewhere, however for completeness it is summarized here. In the wind-off condition the dynamics are controlled by the mechanical stiffness and damping, and in order to extract the aerodynamic contribution it is considered to have the effect of an additional stiffness and damping present during the wind-on experiments. The equation of motion for the freely oscillating rig is:

$$
\ddot{\beta}+\frac{\left(C_{r}-C_{a}\right)}{I_{z z}} \dot{\beta}+\frac{\left(K_{r}-K_{a}\right)}{I_{z z}} \beta=0
$$

where the aerodynamic stiffness and damping are:

$$
\begin{aligned}
& \text { stiffness } K_{a}=N_{\beta}=\frac{1}{2} \rho U^{2} A \ell C n_{\beta} \\
& \text { damping } C_{a}=N_{r}=\frac{1}{2} \rho U^{2} A \frac{\ell}{U} C n_{r}
\end{aligned}
$$
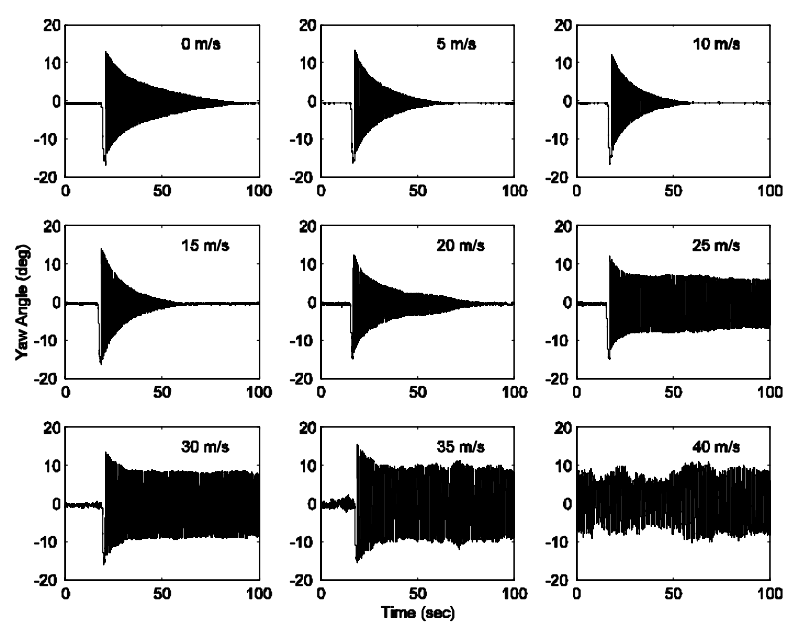

Figure 3. Example time responses.- single spring varying tunnel speed.

The purpose of the analysis is to determine the aerodynamic stiffness and damping derivatives $\mathrm{Cn}_{\beta}$ and $\mathrm{Cn}_{r}$ by considering the wind-on and wind-off data. Some example time responses from the rig are shown in 
figure 3. The figure shows a damped response for windoff and the lower wind speeds, but at a critical speed the oscillation ceases to be damped and a self-sustained response occurs. At higher speeds still $(40 \mathrm{~m} / \mathrm{s})$ no initial displacement of the model is required to generate the oscillation, this is referred to as a self-excited oscillation. The transition away from the damped response is independent of reduced frequency but rather depends on the tunnel speed or Reynolds number.

The aerodynamic stiffness derivative is determined from the normalized yaw moment given by:

$$
\hat{N}_{\beta}=\frac{N_{\beta}}{I_{z z}}=-\left\{4 \pi^{2} f_{o}\left(\left[\frac{f}{f_{o}}\right]^{2}-1\right)+0.6931^{2}\left[\frac{1}{\left(t_{1 / 2}\right)^{2}}-\frac{1}{\left(t_{1 / 2}\right)_{o}^{2}}\right]\right\}
$$

For self-sustained oscillations the second part becomes zero. The frequency ratio is determined in each case from the power spectral density.

The normalized yaw damping is given by:

$$
\hat{N}_{r}=\frac{N_{r}}{I_{z z}}=-1.3863\left[\frac{1}{\left(t_{1 / 2}\right)}-\frac{1}{\left(t_{1 / 2}\right)_{o}}\right]
$$

Where the subscript $o$ represents wind-off condition. For a damped response this can be evaluated using the time series to determine the time to half amplitude of the wind-off and wind-on response. However in the cases of self-sustained and self-excited oscillation this classical approach cannot be used, but an estimate of the aerodynamic damping derivative can be made by assuming that the effective damping ratio is zero (i.e. the aerodynamic damping cancels the mechanical damping) [9]. This allows the cross over point between negative and positive damping to be identified. Below the reduced frequency at which this occurs the damping values do not represent the true aerodynamic damping and give rise to the additional analysis using energy methods described later.

The yaw moment and yaw damping derivatives are then given by: $C n_{\beta}=\frac{\hat{N}_{\beta} I_{z z}}{\frac{1}{2} \rho U^{2} A \ell} \quad C n_{r}=\frac{\hat{N}_{r} I_{z z} U}{\frac{1}{2} \rho U^{2} A \ell^{2}}$

Or alternatively the stiffness derivatives can be nondimensionalised by dividing by the static derivative to provide a magnification coefficient. The static derivatives are determined from the steady balance data and are simply the gradient of the yaw moment and side-force coefficients against yaw angle.

A further feature of the test rig is the option of moving the model mounting point forward from the mid-point of the model. Repeating the experiments with this forward location it is then possible from the paired results to determine the side-force stiffness and damping derivatives.
Side-force derivative

$$
C y_{\beta}=\frac{\left[\left(C n_{\beta}\right)_{\text {mid }}-\left(C n_{\beta}\right)_{\text {front }}\right] \ell}{\Delta \ell}
$$

Side-force damping derivative

$$
C y_{r}=\frac{\left\lfloor\left(C n_{r}\right)_{m i d}-\left(C n_{r}\right)_{f r o n t}\right\rfloor}{\Delta \ell}
$$

The accuracy of the estimation is dependent on the repeatability of the measurement of frequency ratio and time to half amplitude. Based on repeat results for the 20 degree slant the standard deviation of frequency ratio is less than $0.70 \%$. The accuracy of the yaw moment and yaw damping derivatives depends on the tunnel wind speed, giving a standard deviation of $0.2 \%$ at the highest speeds $(40 \mathrm{~m} / \mathrm{s})$ and approximately $2.0 \%$ at $10 \mathrm{~m} / \mathrm{s}$.

In Figure 3 it is also apparent that as the tunnel speed increases the motion becomes increasingly unsteady. The analysis described above is a linearised model of the performance and therefore does not capture this aspect so some further analysis is necessary. This is achieved by considering the intensity of the unsteady component through the sum of the kinetic and potential energies [6]. This technique applies only to the selfsustained oscillations.

$$
E(t)=\frac{1}{2} I_{z z} \dot{\beta}(t)^{2}+\frac{1}{2} I_{z z} \omega_{d}^{2} \beta(t)^{2}
$$

To remove the effect of varying spring stiffness the results are then non-dimensionalised using the wind-off energy to form the energy ratio. The wind-off measurement produces a damped oscillation so the energy is determined between $\pm 10^{\circ}$ down to $\pm 1^{\circ}$.

$$
\frac{E(t)_{o n}-E(t)_{o f f}}{E(t)_{o f f}}
$$

\section{RESULTS}

\section{EFFECT OF SLANT ANGLE}

Figure 4 shows Davis model with various rear slant angle employed in this paper.

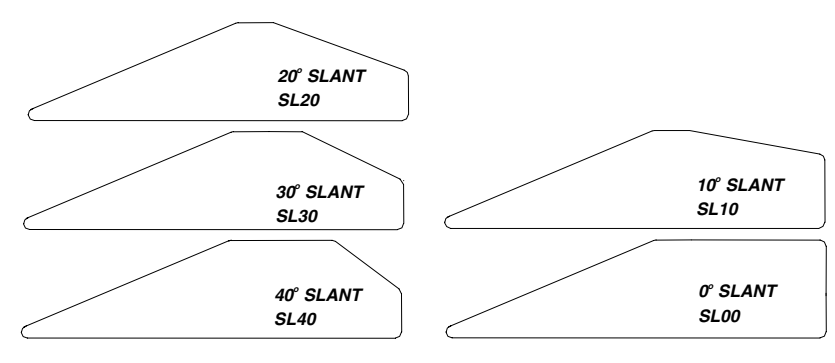

Figure 4 Davis model with various rear slant angle. 
In subsequent figures the abbreviation SL20 and etc are used to denote the test configuration. Figure 5 shows the results for varying slant angle from the steady state tests conducted using the balance
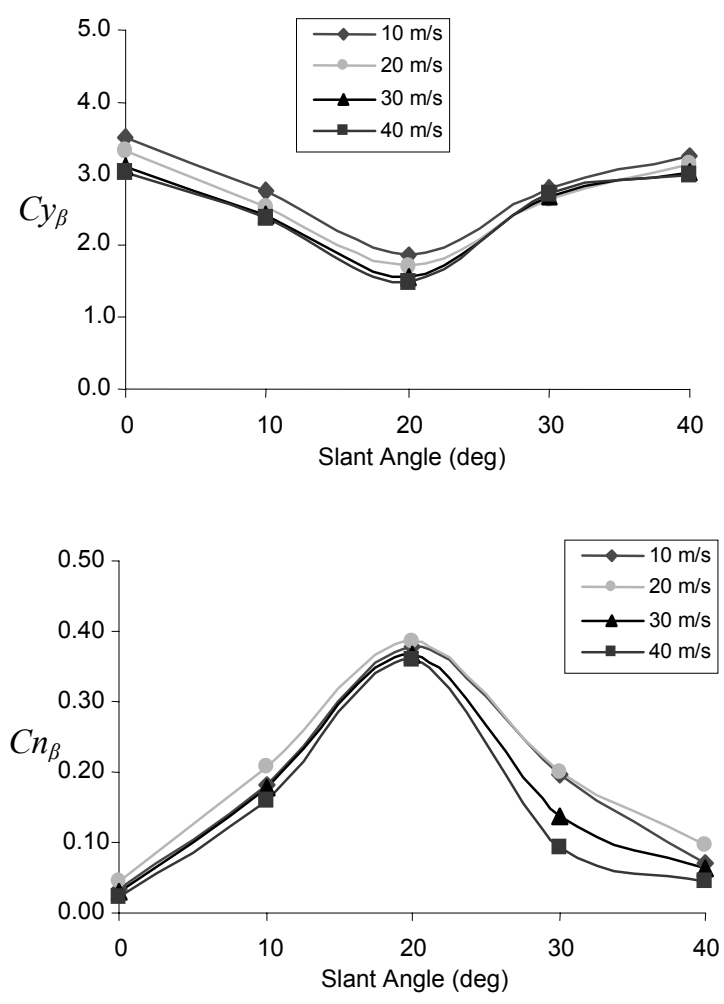

\section{Figure 5 Static side-force and yaw moment derivatives}

The results are presented in the form of side-force and yaw moment derivatives for four tunnel speeds between 10 and $40 \mathrm{~m} / \mathrm{s}$ representing a Reynolds number range of $\left(4.3 \times 10^{5}\right.$ to $\left.1.7 \times 10^{6}\right)$. There is evidently some Reynolds number dependency for all models but this is most pronounced in the yaw moment derivative for the $30^{\circ}$ slant angle. As expected the zero and 40 degree slant angles exhibit the highest side-force derivatives and the 20 degree the largest yaw moment derivative. In the dynamic tests the reduced frequencies are generated from six different springs at four tunnel speed similar to the static tests. The results from the dynamic tests are shown in Figures 6 and 7. In each case the dynamic derivative has been divided by the appropriate static derivative from Figure 5 to generate a magnification factor.

For reduced frequencies below 0.2 the 20 degree slant has the greatest side force magnification with values between 1.5 and 2.0. The zero degree slant has values generally close to unity and the remainder all show values slightly greater than one. At higher reduced frequencies the 10 and 40 degree back angles continue to show responses close to unity but both the 20 and 30 degree slants show large variation, with magnification values ranging from unity to over 2.0.

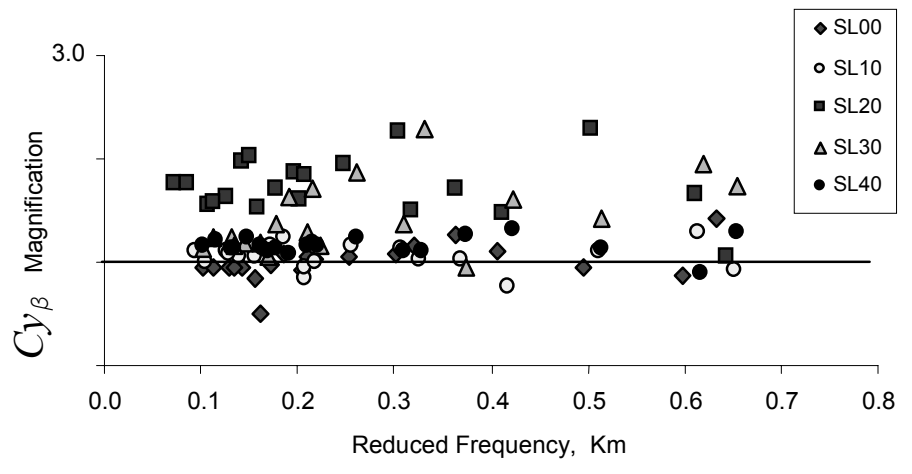

Figure 6 Side-force magnification against reduced frequency for different slant angles.

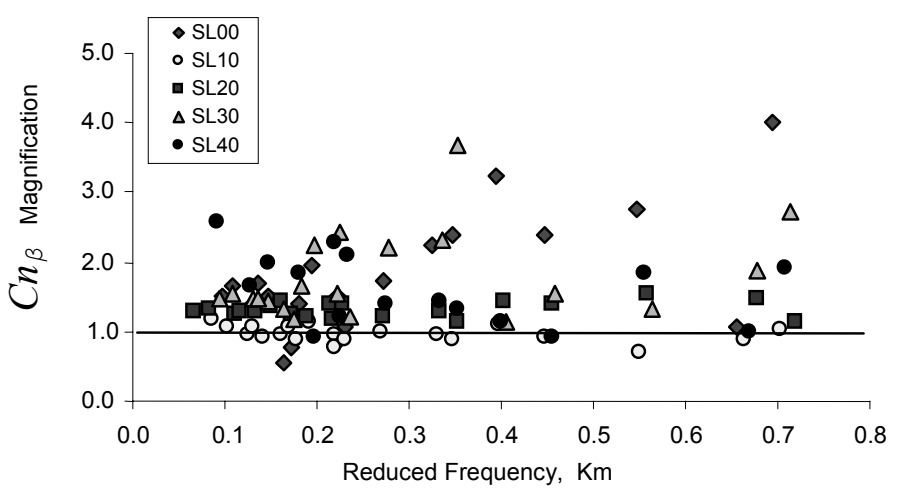

Figure 7 Yaw moment magnification against reduced frequency for different slant angles.

In Figure 7 the yaw moment magnification is close to unity for the 10 degree slant throughout the reduced frequency range, suggesting that the steady state measurements are a good estimate of the transient loads. The 20 degree slant (reported previously [9]) shows transient values between 10 and $40 \%$ higher than the static value. However the zero, 30 and 40 degree slants all exhibit wide fluctuations across the reduced frequency range. With magnification values ranging from close to unity to as much as 4.0. In these cases the steady state data is not a conservative estimate of the dynamic situation. However, the significance of such results will ultimately depend on the loads that these imply on the vehicle. This suggests that it would be worthwhile repeating these tests for a more realistic vehicle shape, to gauge the effect on a real vehicle.

Figure 8 shows the yaw damping derivative as a function of reduced frequency. The approach taken in the analysis means that negative damping derivatives are associated with damped oscillation, with the positive values arising through the assumption of zero effective damping ratio. The figure shows that all models exhibit a damped response at the highest reduced frequency. The 0,10 and 20 degree slants continue to produce damped responses down to a reduced frequency of 0.2 with the 40 degree moving to undamped, or self-sustained oscillation at a reduced frequency of 0.35 . However the 
30 degree slant produces a self sustained oscillation at reduced frequencies of approximately 0.65 .

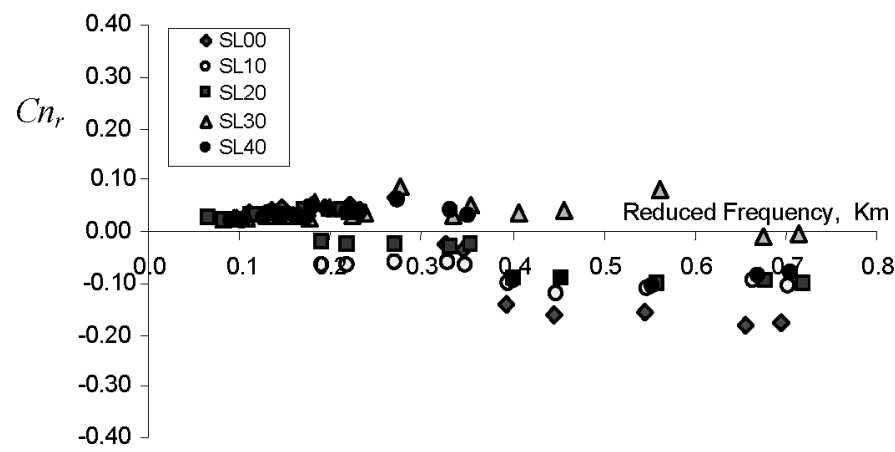

Figure 8 Yaw moment damping derivative

It is well known that the 30 degree slant angle represents a critical angle for transition between a strong three-dimensional flow structure to a less structured turbulent wake. The positive damping values seen for the 30 degree slant are thought to reflect the strong likelihood of regular coupled vortex shedding. It would appear that the critical nature associated with the 30 degree angle, ensures that this shedding occurs across most of the frequency range explored.

As described in the background to the analysis the unsteadiness associated with the self-sustained motion can be represented by the energy ratio. This is shown in Figure 9 for all slant angles at $40 \mathrm{~m} / \mathrm{s}$. It is clear that the 40 degree slant has the greatest energy and therefore the highest levels of unsteadiness, while the 10 degree exhibits the least. To some extent the energy ratio is independent of reduced frequency, however this is not the case for all back configurations, reinforcing the strongly non-linear nature of the problem.

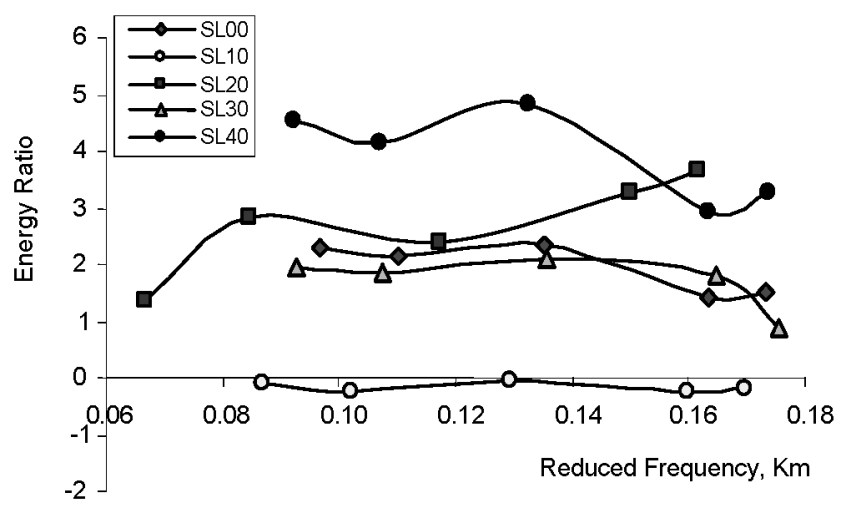

Figure 9 Effect of slant angles on total energy ratio at $40 \mathrm{~m} / \mathrm{s}$.

\section{EFFECT OF C-PILLAR STRAKES}

In addition to the parametric study the 20 degree Davis model was used to investigate the stabilizing effect of attaching strakes to the C-pillar (figure 10). This provides an opportunity to consider the overall suitability of the oscillating model technique in the assessment of simple vehicle modifications.

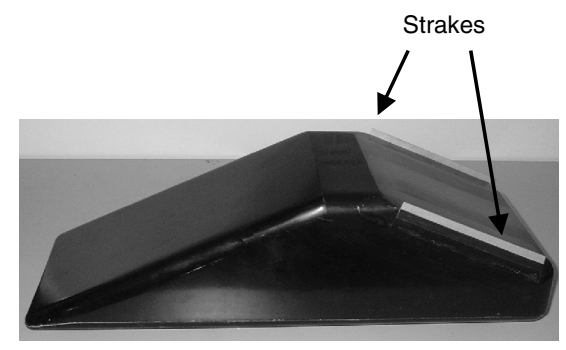

(a)

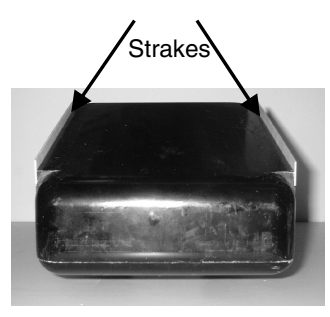

(b)
Figure 10 Model installed with $8 \mathrm{~mm}$ strake (5\% of model height). (a) side view, (b) rear view.
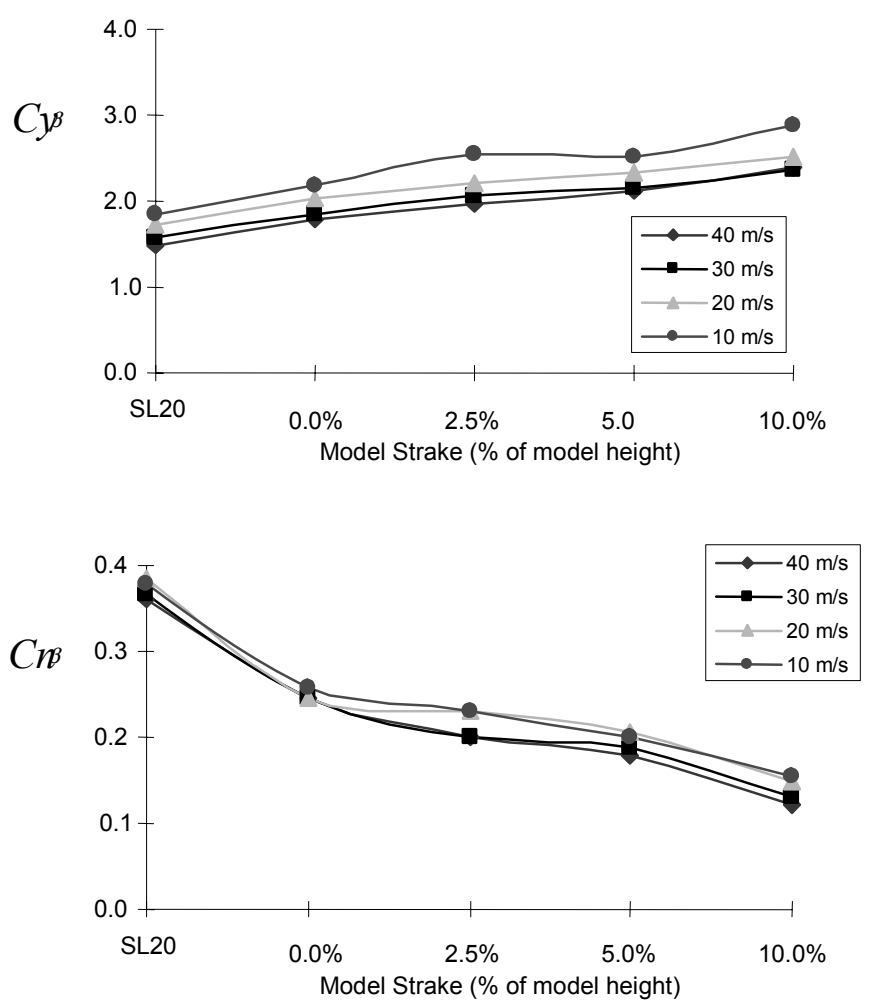

Figure 11 The effect of C-pillar strakes on static derivatives.

Here five configurations are considered. The base model as presented above (SL20), the base model with the $10 \mathrm{~mm}$ C-pillar radius replaced with a sharp edge and three strake heights of $2.5 \%, 5.0 \%$, and $10 \%$. Strake height has been non-dimensionalised using the overall body height. The strakes are attached along the longitudinal edges of the C-pillar fitted flush with the side of the model.

The effect of C-pillar strakes on the static derivatives is seen in Figure 11. The side-force derivative increases progressively with increasing strake size, up by approximately $50 \%$ with the largest installed. The yaw moment derivative reduces over the same range. With the largest strake installed the yaw moment is approximately $60 \%$ of the value for the unmodified 20 degree slant. In both graphs it is also evident that the removal of the C-pillar radius has a significant effect on 
the derivatives. This result shows similar features previously identified by Howell [7] to study the effect of C-pillar radius using conventional static tests.

The side force magnifications calculated from the dynamic tests are shown in Figure 12. The effect of the strakes is clear as the magnification is either close to or below one in all cases. However, there does not appear to be any clear trend to indicate that the larger strakes impart any additional benefit. Removal of the C-pillar radius has a similar effect to the addition of strakes but the effect is not consistent across the reduced frequency range.

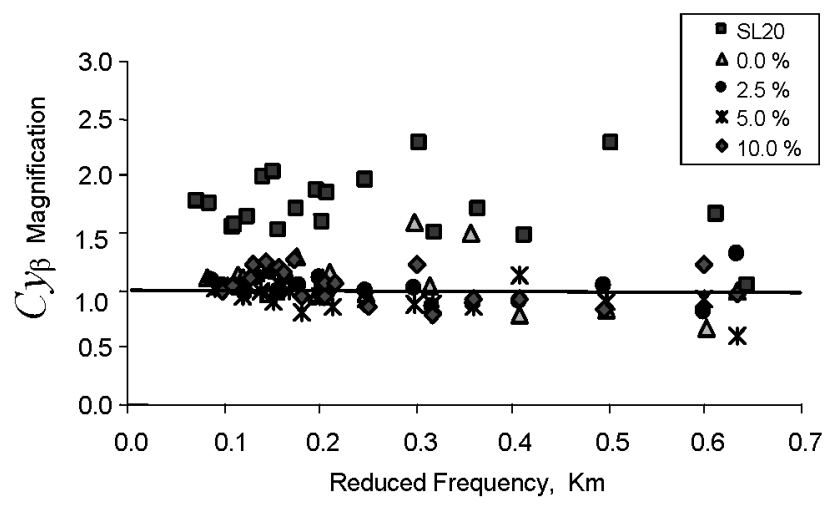

Figure 12 Side-force magnification against reduced frequency for different strakes.

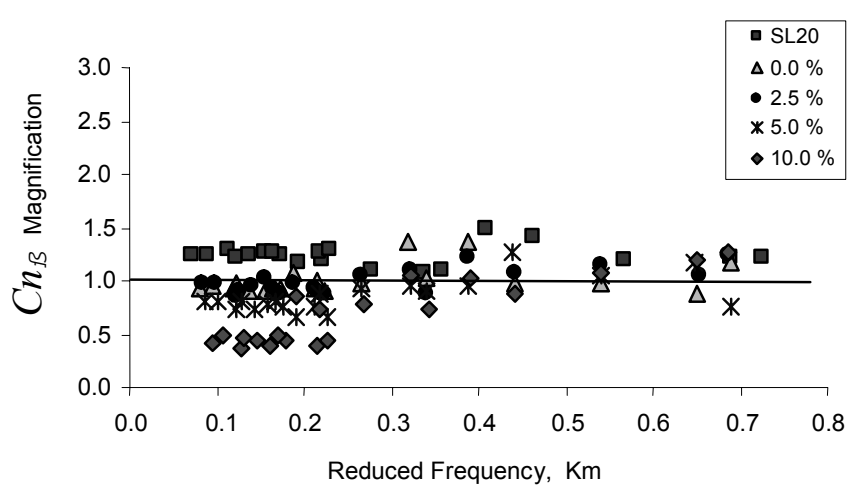

\section{Figure 13 Yaw moment magnification against reduced frequency for different strakes.}

The yaw moment magnification from the same tests is shown in Figure 13. Below a reduced frequency of 0.4 the magnification is generally below one, however above 0.4 the strakes are not as effective. Unlike the side-force results, the height of the strakes appears to be important in the yaw moment data, as progressive increases in the strake size impart an additional stabilizing effect.

The effect of the strakes on the yaw damping derivative (Figure 14) is generally to make the motion more damped. However the cross over point remains at a reduced frequency of approximately 0.2 irrespective of strake size. In practice this means that the model motion becomes self-sustained at the same tunnel speed. The change though is that the amplitude of sustained oscillation is greatly reduced.

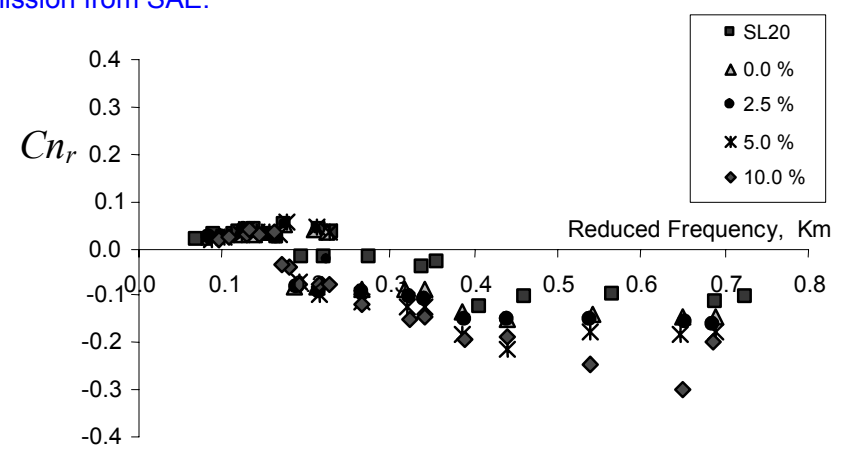

\section{Figure 14 Yaw moment damping derivative for different strakes.}

The energy ratio results shown in Figure 15 show the strong influence of the strakes on the unsteadiness during self-sustained oscillation. However the height of the strakes is again not significant, as the unsteadiness seen in the base model (SL20) is largely removed simply by introducing sharp edges to C-pillar. This would suggest that much of the unsteadiness that exists can be linked to uncertain separation on the C-pillar radius.

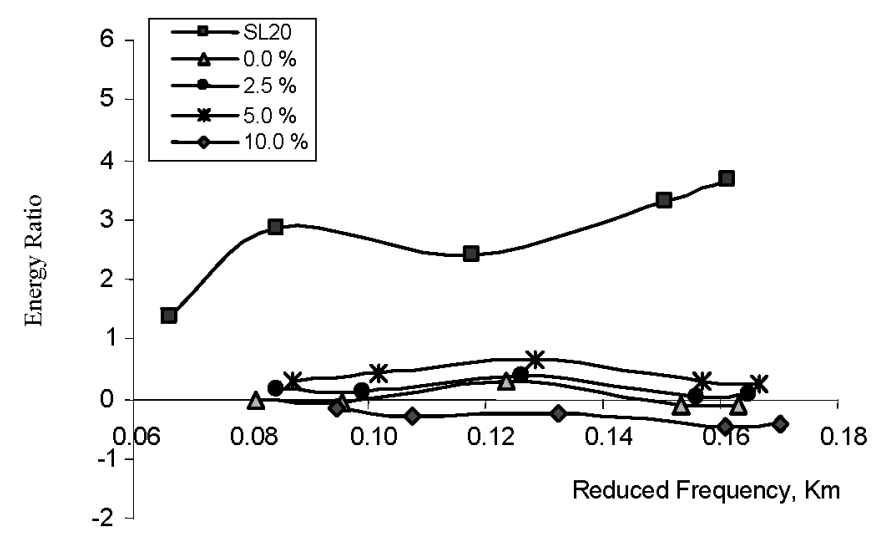

Figure 15 Effect of strakes on total energy ratio at $40 \mathrm{~m} / \mathrm{s}$.

\section{CONCLUSIONS}

- A series of experiments have been conducted to measure the steady and transient side-force and yaw moment response of a simplified car-type bluff body. The input was generated using an oscillating model rig, and the model response determined using angular displacement measurements.

- Transient data acquired over a range of nondimensional frequencies is analyzed to determined side-force and yaw moment aerodynamic magnification factors.

- In the study of the effect of slant angle the results demonstrate that quasi-steady responses are often not a conservative predictor of the true unsteady performance. 
- The intensity of the unsteadiness seen in selfsustained oscillations is strongly dependent on rear slant angle.

- $\quad$ Strakes on the C-pillar are shown to stabilize the flow and reduce the derivative magnification significantly.

\section{ACKNOWLEDGMENTS}

The authors would like to thank the technical staff in the department of Aeronautical and Automotive Engineering for their work in the design and construction of the oscillating model rig. In particular Mr K Coulthard, Mr R Hunter, Mr P Stinchcombe, Mr P Reeves and Mr. G Cunningham.

\section{REFERENCES}

1. Bearman $\mathrm{P}$ W, Mullarkey S P, "Aerodynamic Forces on Road Vehicles due to Steady Side Winds and Gusts", RAeS, Vehicle Aerodynamics Conference, Loughborough, 1994.

2. Chadwick A, Garry, K P, Howell J, "Transient Aerodynamic Characteristics of Simple Vehicle Shapes by the Measurement of Surface Pressure", Vehicle Aerodynamics SAE SP-1524, 2000-010876, 2000.

3. Cooper K R,"Closed-Test-Section Wind Tunnel Blockage Corrections for Road Vehicles", SAE SP1176, 1996.

4. Garry K P, Cooper K R, "Comparison of Quasi-Static and Dynamic Wind Tunnel Measurements of Simplified Tractor-Trailer Models", Journal of Wind Engineering and Industrial Aerodynamics, No. 22, 1986.

5. Goetz H, "Crosswind Facilities and Procedures", SAE SP-1109, Warrendale 1995.

6. Hemon P, Noger C, "Transient Growth of Energy and Aeroelastic Stability of round Vehicle", Journal C. R Mecanique 332 (2004) pg 175-180, Published by Elsevier, 2004.

7. Howell J P,"Shape Features which Influence Crosswind Sensitivity", IMechE C466/036/93, 1993.

8. Macklin A R, Garry K P, Howell J P, "Comparing Static and Dynamic Testing Techniques for the Crosswind Sensitivity of Road Vehicles", SAE 960674, 1996.

9. Mansor S, Passmore M A, "Estimation of Bluf Body Transient Aerodynamics Using an Oscillating Model Rig", Accepted to be published for The Journal of Wind Engineering and Industrial Aerodynamics, Special Edition for $5^{\text {th }}$ International Colloquium on Bluff Body Aerodynamics and Applications - BBAAV" Ottawa, Canada, July 2004.

10. Passmore M A, Richardson S, Imam A, "An Experimental Study of Unsteady Vehicle Aerodynamics", IMechE Part D Journal of
Automotive Engineering, Volume 215 Number 7, July 2001.

11. Russell J B, "Aerodynamic Effects on the Lateral Control and Stability of Motor Vehicles", 1st Symposium on Road Vehicle Aerodynamics, The City University, London, Nov 1969.

12. Ryan A, Dominy, R G, "The Aerodynamic Forces Induced on Passenger Vehicle in Response to a Transient Cross-Wind Gust at a Relative Incidence of $30^{\circ}$, , Developments in Vehicle Aerodynamics, SAE SP-1381, 980392, 1998.

13. Watkins S, Sounders JW, "Turbulence Experienced by Road Vehicles under Normal Driving Conditions", Society of Automotive Engineering, Paper 950997, Special Publication SP-1078.

\section{Notation}

\begin{tabular}{|c|c|c|}
\hline$A$ & - model frontal area & $\mathrm{m}^{2}$ \\
\hline$C_{a}$ & - aerodynamic damping & Nms.rad ${ }^{-1}$ \\
\hline$C_{r}$ & - mechanical damping & $\mathrm{Nms}^{\mathrm{rad}^{-1}}$ \\
\hline$C n_{\beta}$ & - yaw moment derivative & $\operatorname{rad}^{-1}$ \\
\hline \multirow{2}{*}{$\begin{array}{l}C n_{r} \\
C y_{\beta}\end{array}$} & - yaw damping derivative & $\operatorname{rad}^{-1}$ \\
\hline & - side force derivative & $\operatorname{rad}^{-1}$ \\
\hline \multirow{2}{*}{$\begin{array}{l}C y_{r} \\
f\end{array}$} & - side force damping derivative & $\operatorname{rad}^{-1}$ \\
\hline & - oscillation frequency & $\mathrm{Hz}$ \\
\hline$I_{z z}$ & - yaw inertia & $\mathrm{kg} \cdot \mathrm{m}^{2}$ \\
\hline$K_{a}$ & - aerodynamic stiffness & $\mathrm{Nm} \cdot \mathrm{rad}^{-1}$ \\
\hline Km & \multicolumn{2}{|l|}{ - reduced frequency } \\
\hline$K_{r}$ & - mechanical stiffness & Nm.rad ${ }^{-1}$ \\
\hline$\ell$ & - model characteristic length & $\mathrm{m}$ \\
\hline$\Delta \ell$ & \multicolumn{2}{|c|}{ - longitudinal distance from front to mid } \\
\hline$m$ & - model mass & $\mathrm{kg}$ \\
\hline$N_{\beta}$ & - dimensional yaw moment & Nm.rad ${ }^{-1}$ \\
\hline$N_{r}$ & - dimensional yaw damping & Nms.rad ${ }^{-1}$ \\
\hline$\hat{N}_{\beta}$ & \multicolumn{2}{|c|}{ - dynamic normalised yaw moment } \\
\hline & \multicolumn{2}{|l|}{$\mathrm{Nm} \cdot \mathrm{rad}^{-1} / \mathrm{kg} \mathrm{m}^{2}$} \\
\hline$\hat{N}_{r}$ & \multicolumn{2}{|c|}{$\begin{array}{l}\text { - dynamic normalised yaw damping } \\
\mathrm{Nms} \mathrm{rad}^{-1} / \mathrm{kg}^{2} \mathrm{~m}^{2}\end{array}$} \\
\hline$r$ & - yaw rate & $\operatorname{rad} . s^{-1}$ \\
\hline$t$ & - time & $\mathrm{s}$ \\
\hline$t_{1 / 2}$ & - time to half amplitude & s \\
\hline$U$ & - wind tunnel speed & $\mathrm{m} \cdot \mathrm{s}^{-1}$ \\
\hline$\beta$ & - model yaw angle & $\mathrm{rad}$ \\
\hline$\dot{\beta}$ & - model yaw velocity & $\operatorname{rad} . \mathrm{s}^{-1}$ \\
\hline$\ddot{\beta}$ & - model yaw acceleration & $\operatorname{rad} . s^{-1}$ \\
\hline$\rho$ & - air density & $\mathrm{kg} \cdot \mathrm{m}^{-3}$ \\
\hline$\omega_{d}$ & - damped frequency & $\operatorname{rad} . \mathrm{s}^{-1}$ \\
\hline $\operatorname{Re}$ & - Reynolds number & \\
\hline
\end{tabular}

